\title{
Validity and Reliability Testing on Eye Hand Coordination Basketball Players "Overhead and Under Arms Throw"
}

\author{
Roma Irawan $^{1^{*}}$, Heru Syarli Lesmana ${ }^{1}$ \\ ${ }^{I}$ Department of coaching Faculty of Sport Science, Universitas Negeri Padang, Indonesia \\ "Corresponding author.Email: romairawan@fik.unp.ac.id, herulesmana04@gmail.com
}

\begin{abstract}
The aim of this study is to determine the validity and reliability test of eyes and hand coordination of basketball players, namely Overhead and Under Arm Throw. The samples of this study comprised of 58 basketball players from Universitas Negeri Padang and using purposive sampling techniques.The data were analyzed by using Pearson Product Moment to determinethe correlation of the independent and dependent variables. The validity and reliability testinghas been carried out to arrange the norms analysis of eyes and hand coordination by using scale 5 formulas. Based from the result of data analysis; 1) The eyes and hand coordination basketball validity test on Overhead and Under Arm Throw at Universitas Negeri Padang basketball players obtained 0.718 (good). 2) the level of eyes and hand coordination reliability test on Overhead and Under Arm Throw at Universitas Negeri Padang basketball players, obtained 0.875 (acceptable).
\end{abstract}

Keywords: Eyes and Hand Coordination, Validity, Reliability, Basketball

\section{INTRODUCTION}

In the realm of sports, especially the sports in which the level of competition is high, the skills' measurement and evaluation become the important things because the information obtained by the measurement can be used for various purposes, such as doing selection of the students/athletes, grouping them, determining the materials in arranging the exercise programs, determining the methods and tools needed for the exercise, motivating the students/athletes, and determining the appropriate evaluation instruments.

[1] "Test is one of the instruments or procedures used to collect the data of a person and a certain thing or object through certain measurements or rules". Every test administered either in the beginning or at the end of the activity aims to obtain the information or data. The information or data can be obtained by the instruments. Through the instruments, a trainer, lecturer or teacher can then administer the measurement to the respondents.

The test is considered good if it can provide the data correctly. Test analysis is done to identify the test which meets good criteria, such as being considered valid, reliable, objective, and economical; having the assessment norms; having the test instructions/directions; being in the form of duplication of skills; fun; containing educational value. [2] "A test is considered valid if it exactly measures what should be measured." Then, the degree of correctness of a test is called validity. Afterwards, a test is considered reliable if it can measure consistently what should be measured. Therefore, to see the levels of validity and realiability of a test, the degree of coefficient of the test needs to be examined.

One of the most popular sports is basketball. Basketball athletes are demanded to possess fine motor skills, meaning that the quality of their movements should have been improved from the basic level. The development of process in this phase is marked by some progress. The progress can be seen from the following: 1) the less movement errors that occur; 2) the increased roles and functions of the information receiver organs. For instance, for the beginners the most dominant receiver organ is the eye, while for the senior or skillful basketball athletes the information receiver organ was muscle (kinetic); 3) the increased speed of movements performed by the individuals. In order to achieve the good results and acquire the ability to play basketball well, the athletes should undertake the exercise process effectively and obey the rules on the exercise [3].

Doing exercise in sports is the most important thing to make an achievement, especially the physical exercise that refers to a systematic, planned, and progressive exercise program and aims to improve the functional ability of the entire body system so that the athletes' performance will improve. The physical exercise program should be carefully developed and orderly and disciplinedly undertaken. Such discipline includes the measurement test and evaluation. A trainer must be able to select a suitable 
and appropriate test to measure the initial ability of the athletes.

Hand-eye coordination (HEC) is an important physical component in playing basketball. We can see a player dribbling and giving an assist to his/her team-mates in the match to shoot the ball into the basketball hoop. According to [4], coordination is someone's ability to integrate various movements into a single pattern of movement effectively. For instance, in the techniques of dribbling, giving an assist and shooting the ball into the hoop in the basketball match, a player will seemingly have a good motor coordination if (s)he can direct the ball to the target.

There are various physical exercise programs to improve HEC specifically in playing basketball. Usually, each club runs a different physical exercise program for each player, so it depends on what the player is lacking in. In general, there are 5 types of the physical exercise program for the basketball players: 1) speed improvement program, 2) power, 3) agility, 4) endurance, and 5) coordination.

One of the ways to improve the physical condition related to HEC in playing basketball is by providing a good and appropriate exercise. From some physical exercises available, the author has been interested to discuss the exercise of HEC in playing basketball.

Both the lack of test forms on HEC and the lack of trainers' knowledge on using the test of HEC to measure the level of HEC especially in playing basketball are some of the problems in the coaching process. Such problems are possibly due to the absence of effort from the sport observers in developing an appropriate test to measure the level of athletes' HEC ability. Moreover, there have been seemingly no good qualified tests which meet the criteria of good validity and reliability.

The fact in the field has shown that the test forms of HEC have been very limited and there have been no new inventions or innovations on the use of HEC test. Therefore, the authors tried to create or modify the test of HEC specifically in playing basketball. The forms of HEC test have been newly administered and it scopes almost all sports, such as wall-pass by using a tennis ball.

Yet, the researchers have considered that the procedure on the existing test still needs some changes. The procedure is as follows:

1 The subject stands behind the line $2 \mathrm{~m}$.

2 Once there is a signal 'yes', the subject immediately throws the ball into the wall as frequently as possible in 30 seconds.

3 The scores are counted based on the amount of times the player can throw the ball with their right hand and catch it with their left hand, and vice versa within 30 seconds.

4 The ball which hits the ground before it is caught will not be counted.

5 The test can be done simultaneously, if one player is supervised by one supervisor.

Based on the aforementioned explanation, the researcher designed and modified a test which was coordination test of Hand Eye "Throws Overhead and Under Arrest" on basketball.

\section{METHODS}

This study was a descriptive study. 37 basketball players at Universitas Negeri Padang (UNP) were the samples of this study. This study took place at GOR PPSP /Pembangunan Universitas Negeri Padang.

The instrument employed in this study was coordination test "Throws Overhead and Under Arrest" in Basketball which was undertaken by basketball players.

a. The aim was to measure the coordination of basketball players' hand eye.

b. The equipments were: 1) meter, 2) stopwatch, 3) pen and paper, 4) basketball, 5) chalk/ duct tape.

c. The procedures were;

1) The player stood behind the line of $400 \mathrm{~cm}$.

2) Then, after there was a signal "yes", the player directly threw the ball to the wall as many as they could in 60 seconds.

3) The ball was thrown overhead using both hands and the player caught the ball as many as possible within 60 seconds by both hands which were parallel to chest.

4) The player who caught the ball had to be within the circle with a diameter of $100 \mathrm{~cm}$.

5) The ball which hit the ground before it was caught was not counted.

6) The test could be done simultaneously, if one player was supervised by one supervisor.

7) The scores were counted based on the amount of times the ball hit the target in the wall.

8) This test was done three times, and the highest score among them was taken.

Then, there was an assessment norm for male and female players which was applying assessment norms arrangement analysis on the "Throws Overhead and Under Arrest" test using Scale 5 formula. Besides, to analyze the validity of the test, product moment Pearson formula was used.

\section{RESULT}

Based on the procedures of data analysis, descriptive statistical analysis was firstly done. It aimed to get the whole picture of score distribution and present the data. From the analysis, the data obtained were as follows.

\begin{tabular}{|l|l|}
\hline Average & 61.62 \\
\hline Median & 67.00 \\
\hline Mode & 68.50 \\
\hline Standard Deviation & 17.89 \\
\hline Highest Score & 91.50 \\
\hline Lowest Score & 25.50 \\
\hline Variant & 320.02 \\
\hline
\end{tabular}

From the data analysis after correlating the results of HEC test with the HEC test under the judge's observation, the result revealed that the correlation coefficient value was 0.688 . 
In conclusion, HEC test in basketball for basketball player at Universitas Negeri Padang (UNP) was valid. Besides, the validity level of this test on male players could be categorized as good.

The result of data analysis after correlating the first test and second test revealed the correlation coefficient which was 0.876 ; thus, this HECT test was reliable.

To sum up, the validity and the reliability level of Hand Eye coordination test on male basketball players could be categorized as acceptable.

Based on the results of HEC test on basketball players at Universitas Negeri Padang (UNP), it was revealed that most of the players had coordination of hand eye which was categorized as "medium". One of the goals of doing exercise was to improve the physical condition, especially the coordination of hand eye, in playing basketball to score and keep the team's defense. There is no doubt that practice on Hand Eye Coordination (HEC) tasks lead to improvement on EHC tasks [5]. The fit condition enables the players to move and use the perfect technique in basketball match.

The result of validity analysis showed that the validity was in good level. As it has previously been mentioned, the aim of this study was to analyze the reliability and validity of hand eye coordination test "Thrown Overhead and Under Arrest" in basketball. The major finding of this study showed that this test could determine the players' hand eye ability in the match. However, the reliability of this test must be improved in further studies. It is relevantly necessary in developing the reproductive test and it is the requirement to determine the validity for further studies.

Test and retest were done in order to test the reliability of a test. The result showed that reliability of this test was in acceptable level.

\section{CONCLUSION} that:

Based on the findings of this study, it can be concluded

1. The validity of coordination test Hand Eye "Throws Overhead and Under Arrest" on basketball players at Universitas Negeri Padang was 0.718 (good).

2. The reliability of coordination test Hand Eye "Throws Overhead and Under Arrest" on basketball players at Universitas Negeri Padang was 0.875 (acceptable).

\section{REFERENCES}

[1] Nurhasan. Tes dan Pengukuran dalam Pendidikan Fisik. Prinsip-prinsip dan Penerapan. Jakarta: Direktorat Jendral Olahraga. 2001.pp 20-34

[2] Arsil. Evaluasi Pendidikan Jasmani dan Olahraga, Wineka Media, Malang. 2010. pp 30-34

[3] Bompa, O Tudor. Total Training for Young Champions. York University: Human Kinetics. 2004.pp 10-19.

[4] Ismaryati. Tes dan Pengukuran Olahraga. (Surakarta: UNS Press). 2008.pp 30-36
[5] Zupan, M.F., Arata, A.W., Wile, A. \& Parker, R. Visual adaptations to sports vision enhancement training: A study of collegiate athletes at the US Air Force Academy. Clinical Sports Vision. 2015 pp. $43-48$. 